\title{
Treatment-resistant hypertension assessed by home blood pressure monitoring: a new target for intervention?
}

\author{
Michiaki Nagai $^{1} \cdot$ Keigo Dote $^{1}$
}

Received: 11 October 2021 / Accepted: 20 October 2021 / Published online: 18 November 2021

(c) The Japanese Society of Hypertension 2021

Treatment-resistant hypertension (TRH) is associated with an increased risk of adverse cardiovascular (CV) events. Although the pathophysiological mechanisms underlying the development of TRH are poorly understood, sodium intake/ retention, elevated aldosterone levels, and increased sympathetic nervous system activity are predominantly associated with TRH [1]. The European Society of Cardiology (ESC)/ European Society of Hypertension (ESH) guidelines define TRH as the failure to achieve blood pressure (BP) control to levels $<140 / 90 \mathrm{mmHg}$ despite treatment with three antihypertensive medications and at least one diuretic [2]. The American Heart Association (AHA) guidelines adopted an extended definition of TRH that also includes patients who have used four or more antihypertensive medications, even when BP was controlled [3].

Although the importance of the inclusion of out-of-office $\mathrm{BP}$ measurements is emphasized in the definition of TRH, recent guidelines such as those of the ESC/ESH are still based on office BP measurements [2]. Compared with office BP measurement, ambulatory BP measurement (ABPM) minimizes the white-coat effect and therefore provides a better estimate of CV prognoses [4]. The AHA's statement also recommends conducting the evaluation of TRH by using not only ABPM (ABPM TRH) but also home BP (HBP) monitoring (HBPM) [3]. However, there have been no studies of the risk of $\mathrm{CV}$ disease (CVD) in relation to TRH assessed by HBPM (HBPM TRH).

The paper by Narita et al. [5] provides several new insights into the relationship between HBPM TRH and an increased CVD risk that was observed in the nationwide practice-based Japan Morning Surge-Home Blood Pressure (J-HOP) study of 4261 outpatients at high risk of

Michiaki Nagai

nagai10m@r6.dion.ne.jp

1 Department of Cardiology, Hiroshima City Asa Hospital, Hiroshima, Japan developing CVD. Compared with BP that was controlled using $<3$ classes of drugs, the significant adjusted hazard ratios of TRH for total CVD risk were 2.0 and 1.8 for HBPs of $135 / 85 \mathrm{mmHg}$ and $130 / 80 \mathrm{mmHg}$, respectively. In addition, the associations between HBPM TRH and markers of target organ damage (TOD) were suggested to be as strong as those between ABPM TRH and TOD markers, such as the urine albumin-creatinine ratio and plasma brain natriuretic peptide level [5]. HBPM would be useful for an accurate evaluation of the treatment efficacy for additional TRH intervention.

Several pathophysiologies of TRH should be taken into account. Excessive sodium intake is a modifiable cause of TRH. Although the impact of a low-sodium diet on CV morbidity and mortality has been debated, a randomized controlled trial (RCT) in which the effect of salt intake by patients with TRH was examined demonstrated reductions in mean office systolic BP (SBP) and diastolic BP (DBP) of $22.7 \mathrm{mmHg}$ and $9.1 \mathrm{mmHg}$, respectively, in patients following a low-salt diet [6].

Approximately $70-85 \%$ of patients with TRH report obstructive sleep apnea (OSA) [7]. Clinical practice guidelines recommend lifestyle changes and therapy with continuous positive airway pressure (CPAP) in cases of moderate-tosevere OSA [8]. In a meta-analysis of a total of 10 RCTs including 606 participants with OSA plus TRH, CPAP treatment was associated with significant reductions in 24-h SBP and DBP as well as nocturnal SBP and DBP [9].

TRH is highly prevalent among patients with obesity or type 2 diabetes [10]. High values of fasting plasma glucose were found to be an independent predictor of TRH development in the Anglo-Scandinavian Cardiac Outcome Trial (ASCOT) population [11]. On the other hand, in another study, nonseverely obese diabetic elderly patients with uncontrolled nocturnal hypertension showed significant BP reductions with the addition of empagliflozin (a selective sodium glucose cotransporter-2 [SGLT-2] inhibitor) to existing antihypertensive and antidiabetic therapy [12]. Based on this result, it appears that the pleiotropic effects of 
SGLT-2 inhibitors might result in BP reduction in patients with TRH [13].

The overactivation of the renin-angiotensin-aldosterone system has also been suggested as a potential pathological mechanism of TRH [14]. The ESC/ESH guidelines refer to the use of fourth-line mineralocorticoid receptor antagonists (MRAs) [2]. A meta-analysis that included five separate studies and 755 patients revealed that when MRAs were compared with another fourth-line agent or strategy for the treatment of TRH, the MRAs provided larger significant SBP reductions [15].

Although sacubitril/valsartan is the first-in-class agent of dual angiotensin receptor neprilysin inhibitors for the management of heart failure (HF) [16], a randomized, double-blind, placebo-controlled trial for hypertension demonstrated significant SBP and DBP reductions in 24-h, daytime, and nighttime periods in the group of patients treated with sacubitril/valsartan compared to those in the placebo-treated group [17]. Sacubitril/valsartan was shown to be associated with a significant BP reduction in TRH patients with $\mathrm{HF}$ with a preserved ejection fraction (HFpEF). This relationship was also observed in HFpEF patients who continued to have elevated SBP despite treatment with at least four antihypertensive drug classes, including an MRA [18].

Device-based therapies have been used to target TRH. Although interventions for TRH include renal sympathetic denervation (RND) and baroreceptor activation therapy, the use of device-based therapies is not recommended for the routine treatment of hypertension until further evidence regarding the safety and efficacy of such devices becomes available [2].

In the past decade, a technique involving the ablation of sympathetic afferents in the renal artery was developed with initial pilot studies showing a decrease in office SBP of 20-30 $\mathrm{mmHg}$ in patients with TRH [19]. However, the largest sham-controlled RCT, the Symplicity HTN-3 trial, did not report a significant difference between the sham and RDN arms [20]. A subsequent meta-analysis confirmed that the pooled effect from the three sham-controlled RCTs was not significantly different between study arms regarding the BP change observed by ABPM [21]. These findings informed the design of more recent trials that have used different multielectrode catheter designs or ultrasound techniques to ensure more complete ablation [22-24].

These trials did report a significant $\mathrm{BP}$ decrease in ABPM with RDN controlled for sham treatment, albeit at a lower magnitude of 4-6 mmHg. Regarding heart rate (HR), the reductions in mean office, 24-h, daytime, and nighttime SBP values in an RDN group at 3 months were greater among the patients with baseline office HR $\geq 70$ beats/min than among those with $\mathrm{HR}<70$ beats/min, suggesting an association between baseline HR and BP reduction after

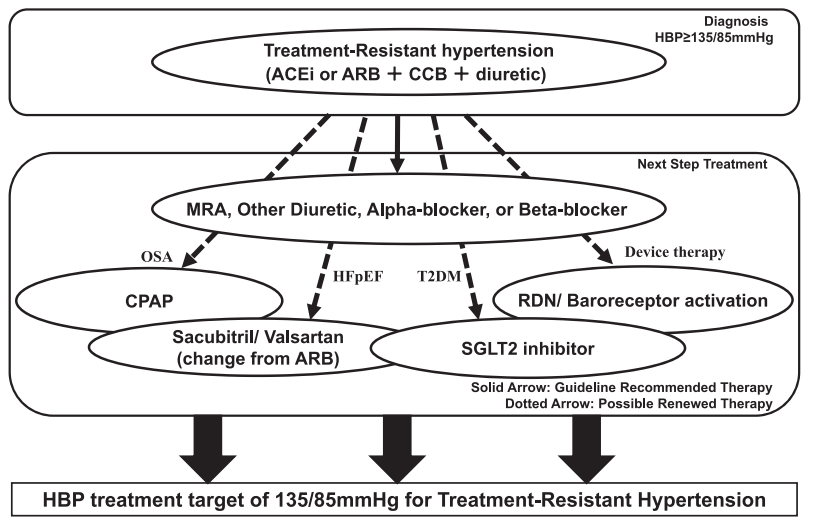

Fig. 1 Possible treatment strategy for treatment-resistant hypertension assessed by home blood pressure (BP) monitoring. Reproduced from Ref. [2]. and Ref. [28]. ACEi angiotensin-converting enzyme inhibitor, ARB angiotensin receptor blocker, CCB calcium channel blocker, CPAP continuous positive airway pressure, HBP home blood pressure, HFpEF heart failure with preserved ejection fraction, MRA mineralocorticoid receptor antagonist, OSA obstructive sleep apnea, RDN renal sympathetic denervation, SGLT-2 selective sodium glucose cotransporter-2, T2DM type 2 diabetes mellitus

RDN [25]. Notably, the follow-up periods in these RCTs were short (from 2 to 6 months), and there are no data about reductions in clinical outcomes from sham-controlled RCTs. Thus, at present, there are insufficient data based on the existing guidelines to recommend the use of RDN in patients with TRH.

Baroreceptor activation therapy relies on the activation of the myogenic stretch reflex in the carotid body, which results in a reduction in sympathetic nervous system activity and BP reduction. After the initial promising pilot RCT data, the pivotal double-blind RCT did not show a significant BP reduction [26]. In addition, $25 \%$ of the participants experienced procedural adverse events [26]. An endovascularly delivered implant device, which increases wall strain in the carotid sinus, has similarly shown promise in a pilot RCT, lowering the $\mathrm{BP}$ measured with ABPM by $21 \mathrm{mmHg}$, with a larger double-blind RCT currently underway [27].

Although several new therapeutic methods have been developed, an accurate evaluation method is needed for the efficacy of TRH therapies (Fig. 1) [2, 28]. HBPM is useful for this, and HBPM TRH has substantial potential to serve as a new target for intervention. As there have been few investigations assessing the relationship between HBPM TRH and CVD incidence, the data presented in the study by Narita et al. [5] make an important contribution to the literature regarding the diagnosis of TRH and the efficacy of TRH treatments.

\section{Compliance with ethical standards}

Conflict of interest The authors declare no competing interests. 
Publisher's note Springer Nature remains neutral with regard to jurisdictional claims in published maps and institutional affiliations.

\section{References}

1. Huynh K. Hypertension: PATHWAY to improving the treatment of drug-resistant hypertension. Nat Rev Cardiol. 2015;12:681.

2. Williams B, Mancia G, Spiering W, Agabiti Rosei E, Azizi M, Burnier M, et al. 2018 ESC/ESH guidelines for the management of arterial hypertension: the task force for the management of arterial hypertension of the European Society of Cardiology and the European Society of Hypertension. J Hypertens. 2018;36:1953-2041.

3. Carey RM, Calhoun DA, Bakris GL, Brook RD, Daugherty SL, Dennison Himmelfarb CR, et al. Resistant hypertension: detection, evaluation, and management: a scientific statement from the American Heart Association. Hypertension. 2018;72:e53-e90.

4. Kikuya M, Hansen TW, Thijs L, Björklund-Bodegård K, Kuznetsova T, Ohkubo T, et al. Diagnostic thresholds for ambulatory blood pressure monitoring based on 10-year cardiovascular risk. Circulation. 2007;115:2145-52.

5. Narita K, Hoshide S, Kario K. Association of treatment-resistant hypertension defined by home blood pressure monitoring with cardiovascular outcome. Hypertens Res. 2021. https://doi.org/10. 1038/s41440-021-00757-4. Epub ahead of print.

6. Pimenta E, Gaddam KK, Oparil S, Aban I, Husain S, Dell'Italia LJ, et al. Effects of dietary sodium reduction on blood pressure in subjects with resistant hypertension: results from a randomized trial. Hypertension. 2009;54:475-81.

7. Martínez-García MA, Navarro-Soriano C, Torres G, Barbé F, Caballero-Eraso C, Lloberes $\mathrm{P}$, et al. Beyond resistant hypertension. Hypertension. 2018;72:618-24.

8. Qaseem A, Holty JE, Owens DK, Dallas P, Starkey M, Shekelle P. Management of obstructive sleep apnea in adults: a clinical practice guideline from the American College of Physicians. Ann Intern Med. 2013;159:471-83.

9. Labarca G, Schmidt A, Dreyse J, Jorquera J, Enos D, Torres G, et al. Efficacy of continuous positive airway pressure (CPAP) in patients with obstructive sleep apnea (OSA) and resistant hypertension (RH): Systematic review and meta-analysis. Sleep Med Rev. 2021;58: 101446. https://doi.org/10.1016/j.smrv.2021.101446.

10. Sarafidis PA. Epidemiology of resistant hypertension. J Clin Hypertens. 2011;13:523-8.

11. Gupta AK, Nasothimiou EG, Chang CL, Sever PS, Dahlöf B, Poulter NR. Baseline predictors of resistant hypertension in the Anglo-Scandinavian Cardiac Outcome Trial (ASCOT): a risk score to identify those at high-risk. J Hypertens. 2011;29:2004-13.

12. Kario K, Okada K, Kato M, Nishizawa M, Yoshida T, Asano T, et al. 24-hour blood pressure-lowering effect of an SGLT-2 inhibitor in patients with diabetes and uncontrolled nocturnal hypertension: Results from the randomized, placebo-controlled SACRA Study. Circulation. 2018;139:2089-97.

13. Pioli MR, Ritter AMV, Modolo R. Unsweetening the heart: possible pleiotropic effects of SGLT2 inhibitors on cardio and cerebrovascular alterations in resistant hypertensive subjects. Am J Hypertens. 2018; 31:274-80.

14. Alvarez-Alvarez B, Abad-Cardiel M, Fernandez-Cruz A, MartellClaros N. Management of resistant arterial hypertension: role of spironolactone versus double blockade of the renin-angiotensinaldosterone system. J Hypertens. 2010;28:2329-35.
15. Sinnott SJ, Tomlinson LA, Root AA, Mathur R, Mansfield KE, Smeeth L, et al. Comparative effectiveness of fourth-line antihypertensive agents in resistant hypertension: a systematic review and meta-analysis. Eur J Prev Cardiol. 2017;24:228-38.

16. Jhund PS, McMurray JJ. The neprilysin pathway in heart failure: a review and guide on the use of sacubitril/valsartan. Heart. 2016; 102:1342-7.

17. Kario K, Sun N, Chiang FT, Supasyndh O, Baek SH, InubushiMolessa A, et al. Efficacy and safety of LCZ696, a first-in-class angiotensin receptor neprilysin inhibitor, in Asian patients with hypertension: a randomized, double-blind, placebo-controlled study. Hypertension. 2014;63:698-705.

18. Jackson AM, Jhund PS, Anand IS, Düngen HD, Lam CSP, Lefkowitz MP, et al. Sacubitril-valsartan as a treatment for apparent resistant hypertension in patients with heart failure and preserved ejection fraction. Eur Heart J. 2021;42:3741-52.

19. Esler MD, Krum H, Sobotka PA, Schlaich MP, Schmieder RE, Böhm M. Renal sympathetic denervation in patients with treatment-resistant hypertension (the Symplicity HTN-2 Trial): a randomised controlled trial. Lancet. 2010;376:1903-9.

20. Bhatt DL, Kandzari DE, O'Neill WW, D'Agostino R, Flack JM, Katzen BT, et al. A controlled trial of renal denervation for resistant hypertension. N Engl J Med. 2014;370:1393-401.

21. Pappaccogli M, Covella M, Berra E, Fulcheri C, Di Monaco S, Perlo E, et al. Effectiveness of renal denervation in resistant hypertension: a meta-analysis of 11 controlled studies. High Blood Press Cardiovasc Prev. 2018;25:167-76.

22. Townsend RR, Mahfoud F, Kandzari DE, Kario K, Pocock S, Weber MA, et al. Catheter-based renal denervation in patients with uncontrolled hypertension in the absence of antihypertensive medications (SPYRAL HTN-OFF MED): a randomised, sham-controlled, proof-of-concept trial. Lancet. 2017;390:2160-70.

23. Azizi M, Schmieder RE, Mahfoud F, Weber MA, Daemen J, Davies J, et al. Endovascular ultrasound renal denervation to treat hypertension (RADIANCE-HTN SOLO): a multicentre, international, single-blind, randomised, sham-controlled trial. Lancet. 2018;391:2335-45.

24. Kandzari DE, Böhm M, Mahfoud F, Townsend RR, Weber MA, Pocock S, et al. Effect of renal denervation on blood pressure in the presence of antihypertensive drugs: 6-month efficacy and safety results from the SPYRAL HTN-ON MED proof-of-concept randomised trial. Lancet. 2018;391:2346-55.

25. Böhm M, Tsioufis K, Kandzari DE, Kario K, Weber MA, Schmieder RE, et al. Effect of heart rate on the outcome of renal denervation in patients with uncontrolled hypertension. J Am Coll Cardiol. 2021;78:1028-38.

26. Bisognano JD, Bakris G, Nadim MK, Sanchez L, Kroon AA, Schafer J, et al. Baroreflex activation therapy lowers blood pressure in patients with resistant hypertension: Results from the double-blind, randomized, placebo-controlled rheos pivotal trial. J Am Coll Cardiol. 2011;58:765-73.

27. Spiering W, Williams B, Van der Heyden J, van Kleef M, Lo R, Versmissen $\mathrm{J}$, et al. Endovascular baroreflex amplification for resistant hypertension: a safety and proof-of-principle clinical study. Lancet. 2017;390:2655-61.

28. Umemura S, Arima H, Arima S, Asayama K, Dohi Y, Hirooka Y, et al. The Japanese Society of Hypertension guidelines for the management of hypertension (JSH 2019). Hypertens Res. 2019; 42:1235-481. 